\section{NOTE ON THE THERAPEUTICS OF SUGAR.}

BY

Sir JAMES SAWYER, M.D.Lond., F.R.C.P., SENIOR CONSULTING PHYSICIAN TO THE QUEEN'S HOSPITAL, BIRMTNGHAM.

THe profession is much indebted to Dr. Goulston for his paper in the JodRNAL* showing forth the good effects of the exhibition of sugar in certain forms of cardiac failare. His therapentic suggestions rest upon sound physiological foundations, based upon recent experimental research, and, illustrated as they are by clinical records of results in medical practice, they promise to become one of the greatest additions to our remedial resources in failure of the musculatare of the heart of later years.

I desire now to record that I have used cane sugar freely and frequently during the last ten years or so with success in a variety of morbid conditions. In wasting disorders, in varions forms of ansemia, in adjnamic varieties of rheumatism, and especially in the neurasthenic manifestations of neurotic persone, I have found the continued ingestion of cane sugar markedly beneficial, incressing weight and power, and appearing to act not merely as a nutrient bat also as a tonic in the best senses of that word -namely, as a very valuable medicine, "the continued administration of which in debilitated and relaxed con. ditions of the body imparts strength and vigour without producing any sudden excitement,"' and as a corroborant gently stimulating the vital energies to an aroused action by a kind of mild stimulation, slowly produced and permanent in effect. For an adult I have usually prescribed from a quarter to half a pound of lump cane sugar, to be slowly eaten-daily, a lump or two to be taken at odd times through the day or night, but not just before a meal, the patient always sarrying a little store of the remedy with him, and eating some of it when so disposed.

Now we shall have to think of members of the sugar group especially as sustainers and developers of the musculature of the heart, as in failure of compensation, and in a large variety of cardio-vascular troubles. It would seem that our obstetrio brethren might find the remedy useful in conditions of uterine atony, say as a particular nutrient during pregnancy.

I have found it useful to recollect that cane sugar may be distinguisbed from other forms of sugar by its luminosity in the dark when two lumps are rubbed together.

REFERENCE.

1 Neligan's Medicines, etc.

\section{The CardigaN CANCER CURES.} BY

G. M. DAWKIN, M.R C.S., L.R.C.P., PONTYPRIDD.

IT was my lot to visit the town of Cardigan during the time when the cures had been boomed, and when there were scores of people going there for treatment, some of them with malignant growth, some for benign, but all diagnosed as cancerous.

My first visit was with a lady patient who was suffering from cancer of the throat; she had seen several London specialists, including Sir Felix Semon, and the case was considered quite inoperable and hopeless by him and by Mr. Tilley. On the evening of our arrival the two brothers came to visit her and examined her throat. The growth was pharyngeal, and invaded the posterior part of one tonsil; but this state of affairs did not.prevent them from assuring her that she might confidently expect recovery, as they had cured worse cases. They gave some oil which had to be rubbed on the neck, and treatment was continued for couple of months, when the end came, not in the promised recovery, but in death.

The second patient of mine who went there was an elderly man with cancer of the lip, which he had refused to have removed by operation. When $I$ saw him in

*Note on the Beneficial Effect of the Ingestion of Cane Sugar in Certain Forms of Heart Disease. BRITISH Madrcal JodRNAI, March
Cardigan he was quite hopeful, and considered the treatment was doing him good, but I could find no reason for this belief except that he was having a, great deal of pain, and he had been assured that this was a most desirable thing, as the remedy had now reached the roots of the cancer, which were being tugged away. He came home in about six weeks worse than he went, and ultimately died of his disease.

A painful feature of this case had reference to his daughter, who had accompanied him to Cardigan. For some resson or other she had been induced to show her breasts to the "doctors," and cancer was at once diagnosed and active treatment commenced on the right breast. When she returned to Pontypridd she was given some powder and oil to apply according to their instruc. tion. The treatment was most agonizing, and I was asked to see her. The breast was simply raw; all the skin had been completely eaten away; there was nothing in the breast beyond the ordinary glandular structure, and the treatment was stopped and the breast healed up under ordinary treatment. She was only about 27 ; and she was married last year, giving birth to a child recently, and, of course, suffering from the inconvenience of having her right breast useless.

A third case came under my notice, that of an elderly lady with cancer of the breast. After nearly twelve months she came home to die. It was on my first visit to Cardigan that I was told that Mr. W. T. Stoad had sent down a test case, and I went to see him. This man's name was Drummond, and he stayed at Adelphi House. He was, I should think, about 40 years of age, and lived in either East or West Ham. He told me he had been at several hospitals, and was a patient at the Middlesex before coming down to Cardigan. When I saw him he told me that the "cancer doctors" were very hopeful about his case, and he too, poor fellow, had been inspired with a hope that was to be falsified very soon. I found that he had a sarcoma on the left side of the neck as large as a small orange. He had been under treatment for several weeks, and the surface of the tumour was almost black and cracked in several places, suggesting that it had been treated with some strong escharotic like chloride of zinc. The application of the remedy gave much pain, but here, as in other csses, the pain was considered as a clear indication that the growth was being eradicated. I saw Drummond about three times at intervals of about three weeks. There was no change in the tumour except that the surface was fissured and a little shrunken. Soon after my last visit he returned to London and died.

A fifth case that I saw was a man with cancer of the throst. Here again a most cheerfal view was taken, and great hope given, all to end as usual-in death.

The faith that even educated people place in quackery was curiously illustrated by a lady whose husband was a relative of a distinguished physician. She was supposed to be suffering from cancer of both breasts, and was undergoing very active and agonizing treatment. I was allowed to examine her breast, and the gland had been practically eaten away by some eroding agent. The detached parts which fell from the breast when I examined it had the appearance of mortar, and crumbled on pressure. No antiseptic treatment was followed, but in spite of this there was nothing offensive or putrescent about it, showing. I suppose, that some powerful mineral had been employed in the remedy.

In no case have I known an authentic and unquestion. able malignant growth yielding to the Cardigan cure, and I think all the boomed successes are cases of warts, fibromata, and other non-malignant conditions.

A PAḾPHLET, under the title of No Irish need Apply and intended for circulation among the public, sets forth the views of the Association of Fellows of the Royal College of Surgeons of Ireland as to the impropriety of the regulations of any English hospital being so framed as to limit candidature for appointments on the surgical staff to those possessed of the diploma of fellowship of the Royal Colleg of Surgeons of England, thus excluding, among others, persons possessed of diplomas and degrees from Irish corporations and universities. By way of illustration is appended a recent correspondence between the associa. tion and the authorities of the Manchester Royal Inflrmary and some comments thereon by the medical journals. The pamplet is stated to be the first of a series. 